\title{
Effects of pre-harvest techniques in the control of berry ripening in grapevine cv. Sauvignon blanc
}

\author{
Valentina Lucchetta, Benedetta Volta, Mattia Tononi, Damiano Zanotelli and Carlo Andreotti \\ Free University of Bozen-Bolzano, Faculty of Science and Technology, 39100 Bolzano-Bozen, Italy
}

\begin{abstract}
Due to a variety of reasons (changing climatic conditions, higher photosynthetic efficiency of newly established vineyards, yield restriction imposed by production protocols), there is currently a tendency towards early ripening in grapevines, combined with the production of berries characterized by high sugar content. This tendency conflicts with the general market demand for wines (mostly white wines) with low alcohol level and characterised by a fresh, easy-to-drink taste. We tested two different techniques applied to the canopy (defoliation and the use of an antitranspirant product) with the aim of delaying the ripening process and improving the berry quality of the white cultivar Sauvignon blanc. The defoliation performed at veraison allowed postponement of the ripening process by about 5 days as compared to undefoliated vines, without altering the sugar/acid ratio of the berries. The antitranspirant product delayed ripening by 10 to 15 days. Brix was reduced by 1.5-2.5 degrees in the 2 considered seasons, whereas the effect on acidity was contradicting and needs further research for a full understanding of the mechanisms involved in the process.
\end{abstract}

\section{Introduction}

The current demand of the global wine market is generally directed toward wines characterised by low alcohol levels, freshness and distinct aroma. Low alcohol wines are more adapted to the several societal and political desires to reduce alcohol intake and are, also, more in accordance with the lower legal level of alcohol allowed in the driver's body in most of the countries [1]. This market demand largely conflicts with a general tendency toward berries which show higher sugar content as a result of the changed climatic conditions (higher temperature and $\mathrm{CO}_{2}$ concentration in the atmosphere), the higher photosynthetic efficiency of newly established vineyards, and the implementation of production protocols aiming for reduction of the yield per hectare [2,3]. In addition, the early onset of grapevine phenological stages can move up the biosynthesis and accumulation of secondary metabolites (aromatic and phenolic compounds) during the hottest part of the season, with detrimental effects on final wine quality (flat wines, characterized by altered bouquet and off-flavor, with lower acidity) [4;5].

With the aim of contrasting both the early onset of the ripening process and the accumulation of too high level of sugars in the grapevine berries, different cultivation strategies have been proposed. Beside the strategies which involve major modification of the winegrowing sector (geographical and topographical redistribution of the vineyards, reconsideration of the genotypes assortment within the existing protected designation of origin discipliners) $[2,4]$, there are shortterm solutions based on differential technical approaches for the management of the grapevine canopy which can be successfully adopted. These techniques can be classified in two groups. The first group involves practices that aim to enhance the competition between vine organs. These are represented by techniques in which a calibrated reduction of the leaf area to cluster ratio is imposed by means of several shoot trims at different phenological stages or by calibrated leaf pulling close to the cluster zone $[6,7,8]$. The second group focuses on the promotion of a temporary limitation of the environmental inputs for the photosynthesis. This can be implemented by several means, such as the use of shading nets (lowering the photosyntetically active radiation) or by the application of antitranspirant to the canopy (lowering the gas exchange rates), with the final goal of slowing down and reducing the accumulation of sugars in berries $[9 ; 10 ; 11 ; 1213 ; 14]$.

The detrimental effects of too warm climatic conditions on the primary (sugars) and secondary (aromatic and phenolic compounds) components of berry quality are particularly strong on white grapevine cultivars. Despite this evidence, the majority ofstudies dealing with differential canopy management approaches to postpone grape maturation have been conducted on red cultivars (Sangiovese, Aglianico, Sagrantino, etc.) and in wine growing regions located in central Italy. Therefore there is, in our opinion, the need to test these techniques also on white grapevine varieties cultivated in northern, mountainous regions, which are currently those

* Corresponding author: carlo.andreotti@,unibz.it 
mostly affected by climatic changes [15]. To do so, we investigate, during two distinct growing seasons, the efficacy of different canopy management techniques (defoliation and antitranspirant applications) to delay the ripening process of Sauvignon blanc grapevines cultivated in Alto Adige, an important wine production district in north-east Italy.

\section{Material and methods}

\subsection{Plant material and experimental layout}

The trial was conducted over 2 years (2015 and 2017) in the experimental vineyard of the Free University of Bozen-Bolzano located in the municipality of Ora-Auer (Alto-Adige/South Tyrol, north-eastern Italy) on a soil classified as sandy-loam. Vines belonged to the cv. Sauvignon blanc, grafted on SO4 rootstock. Planting density was around 6,250 vines per hectare (spaced $0.8 \mathrm{x}$ $2 \mathrm{~m}$ ), rows were southeast oriented and the training system was a unilateral Guyot with approximately 12 nodes per vine retained at winter pruning. The vineyard was equipped with a drip irrigation system and maintained under the local integrated vineyard management guidelines as for fertilization, pest and weed management (http://www.beratungsring.org).

Three treatments were applied in a randomized block design: i) untreated control; ii) defoliation; iii) antitranspirant spray. Within each block, treatments were randomly applied on six vines per plot (30 vines per treatment in total). To avoid any contamination between treatments, plots on the same row were separated by at least six vines (one post spacing), whereas vines on the adjacent rows facing the treated plots were excluded from any experimental treatments. The defoliation was performed at veraison by manually pulling around one third of the leaves that were present on the primary shoots, therefore creating a window of $30-40 \mathrm{~cm}$ above the cluster zone (Fig. 1). The treatment with the antitranspirant was performed with a commercial product named Vapor Gard (Biogard ${ }^{\mathbb{B}}, \mathrm{CBC}$ - Europe S.r.l., Italy). Vapor Gard contains 1-p-menthene as active ingredient $(96 \%)$ and, after mixing with water at $2 \%$ concentration, it forms a transparent thin film on the treated leaf surface that reduces gas exchanges. Vapor Gard application was performed once at veraison in 2015 and twice in 2017 (at bunch closure and at veraison). Sprays were conducted at sunset on the entire canopy with a shoulder pump until run off.

The experimental vineyard was also equipped with a weather station (iMetos AG/CP/DD 280, Pessl Instruments $\mathrm{GmbH}$ Weiz, Austria), measuring minimum and maximum temperature, air humidity and rainfalls.

\subsection{Leaf photosynthesis}

The effects of the different treatments on leaf photosynthetic rate was monitored with a portable gas exchange analyser (ADC Bioscientific. Ltd, Hoddesyon, UK).
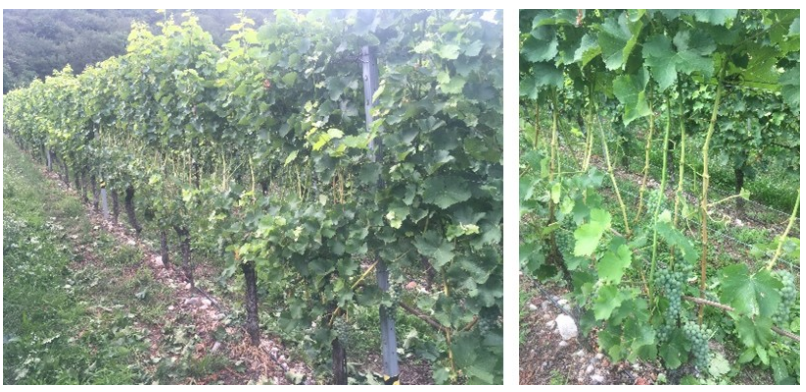

Fig. 1. Manual leaf pulling performed at veraison, above the cluster zone (defoliation treatment)

The photosynthetic rate $\left(\mathrm{A}, \mu \mathrm{mol} \mathrm{CO}_{2} \mathrm{~m}^{-2} \mathrm{~s}^{-1}\right)$ was measured at approximately seven-day intervals from veraison (2015) or bunch closure (2017), until harvest period. Two fully expanded mature, south-exposed leaves inserted on the main shoot were selected from each experimental unit. The measurements were taken under saturating light conditions $(1800 \mu \mathrm{mol}$ photons $\left.\mathrm{m}^{-2} \mathrm{~s}^{-1}\right)$ at midday $(11: 00-13: 00 \mathrm{~h})$ using a broad leaf gas chamber with a window size of $6.25 \mathrm{~cm}^{2}$ and a flow rate of $400 \mathrm{ml} \mathrm{min}^{-1}$.

\subsection{Yield components, berry ripening and composition}

Berry ripening dynamic as affected by treatments was monitored at weekly interval from veraison to complete maturation. Samples of 50 berries per replicate were collected at each sampling date and prepared for analysis. Values of soluble solid content (SSC) were measured with a digital refractometer (Atago, Tokyo, Japan) on fresh extracted fruit juice and reported in degrees Brix $\left({ }^{\circ} \mathrm{Bx}\right)$. For the analysis of the titratable acidity (TA), $5 \mathrm{~mL}$ fresh extracted grape juice was mixed with $20 \mathrm{~mL}$ distilled water and automatically titrated (Titration Unit Titro-Line easy; Schott Instruments, Mainz, Germany) with a solution of $0.1 \mathrm{~mol}$ $\mathrm{L}^{-1} \mathrm{NaOH}$ to a final $\mathrm{pH}$ of 8.1. The final result was expressed as $\mathrm{g} \mathrm{L}^{-1}$ of tartaric acid. Yield performances as affected by treatments were determined at vintage by measuring individual vine production, number of cluster per vine and average cluster weight. Average berry weight was determined by individually weighting 50 randomly selected berries per treatment at harvest.

\subsection{Statistical analysis}

A two-way analysis of variance on the randomized block design was used to analyse treatment and year effect on measured yield components, whereas a one-way analysis of variance was applied for gas exchanges measurements and ripening curves for year 2015 and 2017 separately (SigmaPlot 12 software package, Systat Software Inc., San Jose, CA, USA). Mean comparison was performed by Tukey Test at $\mathrm{P} \leq 0.05$.

\section{Results and discussion}




\subsection{Weather conditions and effects of treatments on yield performances}

Differences in the climatic conditions of years 2015 and 2017 were overall limited when the average temperature and the growing degree days (GDD) were compared (Fig. 2, left). Only the month of July was significantly warmer in 2015 than in 2017. Differently, the two considered years were clearly distinguished by the rainfall distribution and consistency (Fig. 2, right). 2017 was a relatively wet year, with cumulative rainfalls during the vegetative season that were more than $30 \%$ higher than in 2015. Rainfalls were particularly abundant at beginning of the season, during fruit set, and in midsummer (June-July) before veraison.

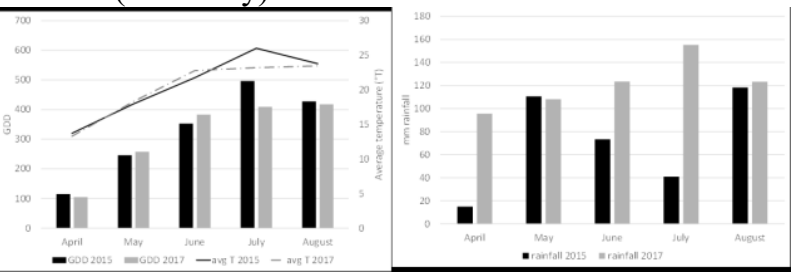

Fig. 2. Meteorological conditions of years 2015 and 2017. Left: average monthly temperatures and growing degree days (GDD, base temperature $10^{\circ} \mathrm{C}$ ). Right: cumulated monthly rainfalls in 2015 and 2017

These weather conditions had an effect on vine yield performance. Independently of the treatment applications, average yield per vine was significantly higher in 2017 than in 2015 (Table 1). This result was driven by the higher number of berries per cluster and, consequently, by the heavier average bunch weight measured in 2017 as compared to 2015. Year 2017 rainfalls might have increased the water availability for vines during the blooming phase, therefore positively influencing fruit set and berry development in the early stages with an overall result of a greater final yield per vine.

Treatment had no significant effect on yield components of the vines, the final yield per vine being around $2-2.3 \mathrm{Kg}$.

Table 1. Yield performance as affected by treatments and year of application ( $n s$ : not significant; ${ }^{* * *} P<0.001$ ).

\begin{tabular}{|l|c|c|c|c|}
\hline & $\begin{array}{c}\text { N. of } \\
\text { bunches } \\
\text { per vine } \\
\text { (N.) }\end{array}$ & $\begin{array}{c}\text { Avg. } \\
\text { bunch } \\
\text { weight } \\
\text { (g) }\end{array}$ & $\begin{array}{c}\text { N. of } \\
\text { berries } \\
\text { per } \\
\text { bunch } \\
\text { (N.) }\end{array}$ & $\begin{array}{c}\text { Avg. } \\
\text { yield } \\
(\mathrm{Kg} \\
\left.\text { vine }^{-1}\right)\end{array}$ \\
\hline Treat. (T) & & & & \\
\hline Control & 14.32 & 162.39 & 91.83 & 2.29 \\
\hline Defoliation & 12.52 & 159.96 & 87.55 & 2.04 \\
\hline Antitransp.t & 15.03 & 155.66 & 83.61 & 2.37 \\
\hline Signific. & $n s$ & $n s$ & $n s$ & $n s$ \\
\hline Year (Y) & & & & \\
\hline 2015 & 14.07 & 133.70 & 67.5 & 1.92 \\
\hline 2017 & 13.84 & 184.97 & 107.9 & 2.55 \\
\hline Signific. & $n s$ & $* * *$ & $* * *$ & $* * *$ \\
\hline TxY & $n s$ & $n s$ & $n s$ & $n s$ \\
\hline & & & & \\
\end{tabular}

\subsection{Photosynthetic performance of vines during} the growing seasons
The antitranspirant Vapor Gard significantly reduced the photosynthetic rate of leaves after the application at veraison in 2015 (Fig. 3, above). This inhibitory effect disappeared approximately two weeks after the spray, when treated and untreated leaves showed similar photosynthetic rates around 15-18 $\mu \mathrm{mol} \mathrm{CO}_{2} \mathrm{~m}^{-2} \mathrm{~s}^{-1}$. Vapor Gard also significantly reduced leaf photosynthesis after the first application at bunch closure, but was ineffective with the second application at veraison (year 2017, Fig. 3, below). A transient inhibition of leaf photosynthetic rate by Vapor Gard was also described on the red grape cultivars "Sangiovese" $[11,13]$ and "Barbera" [14]. The persistency of the treatment effect is, of course, very much dependent on the weather conditions and, specifically, on the timing of precipitation after product application. The partially inconsistent results obtained in the second year of the experiment, despite the fact that the antitranspirant was applied twice during the vegetative season, might be ascribed to the particularly rainy season that characterised the summer of 2017, especially during the month of July. In other words, rainfalls short after treatment application might have washed away the product, therefore limiting its persistency on the canopy and overall efficacy.
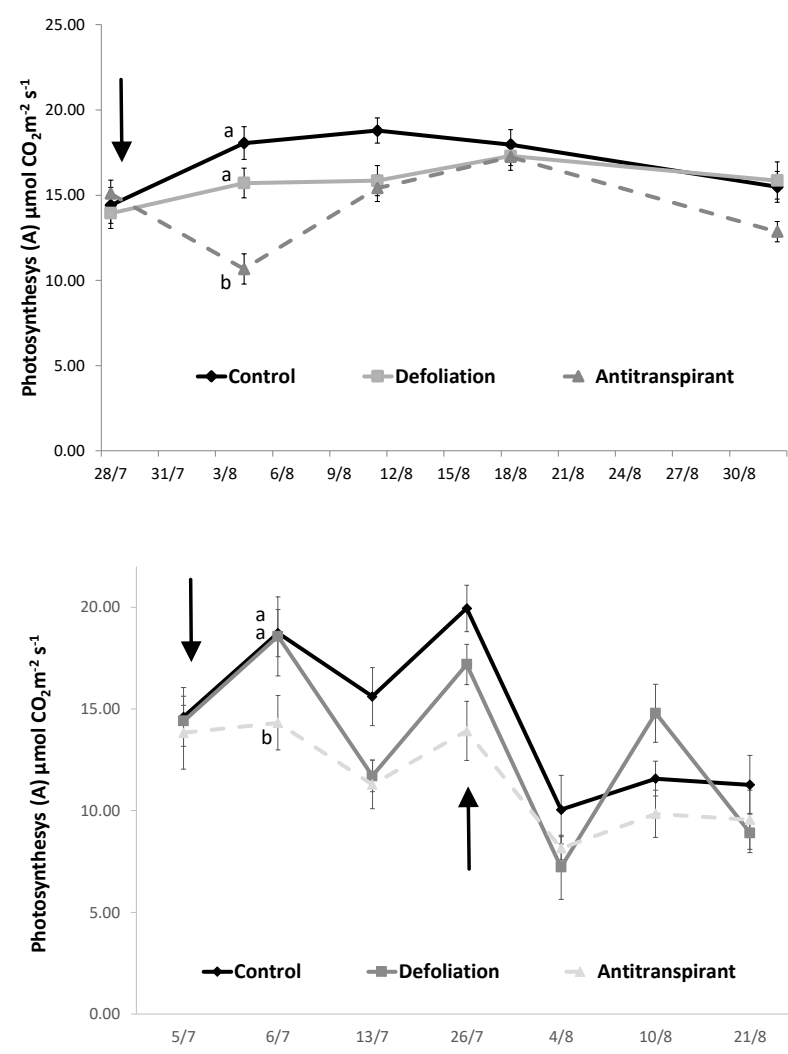

Fig. 3. Photosynthetic rates (year 2015 above and year 2017 below) as affected by treatments. The arrows indicate the time of treatment application (letters indicate significant differences at $P<0.05$ )

\subsection{Berry ripening dynamic and composition}

Ripening curves for SSC showed that the antitranspirant applications were effective in delaying sugar 
accumulation in both years (Fig 4). At harvest time, when control berries reached $22{ }^{\circ}$ Brix, antitranspiranttreated berries presented significantly lower values $(-1.5$ and $-2.4{ }^{\circ}$ Brix in 2015 and 2017, respectively). The defoliation treatment also significantly reduced SSC during season 2015, whereas it was ineffective in 2017. TA resulted higher in antitranspirant-treated berries at harvest 2015, whereas it was lower (as compared with control) in the last sampling of year 2017. Berries from defoliated vines presented TA values no different from the control in 2015, whereas it was lower in 2017.

Previous studies conducted on red grape cultivars (Sangiovese, Ciliegiolo, Barbera, Aglianico) in different cultivation environments, reported similar effect of pre and post-veraison sprays with antitranspirant on sugar accumulation in the berries $[10,12,14,16]$. Our findings therefore confirmed, for the first time, the efficacy of the antitranspirant compounds for the control of sugar accumulation in an early-ripening white cultivar such as Sauvignon blanc. As for the effect of antitranspirant applications on grape acidity, results were dependent on the time of application. Early treatment (pre-veraison), followed by a second application at veraison, decreased final berry titratable acidity. Conversely, when the antitranspirant was applied once at veraison (year 2015), final TA was increased in treated berries. Low berry acidity in early-ripening white cultivars growing in warm areas is often problematic for the production of quality wines.

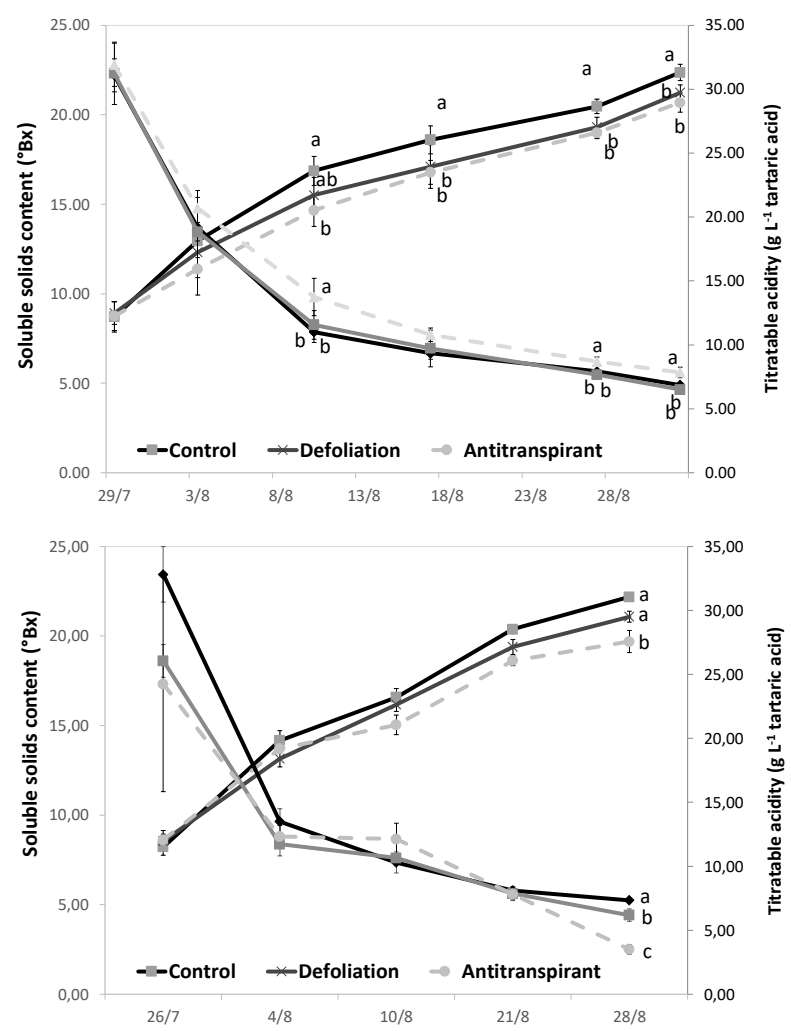

Fig. 4. Dynamics of soluble solids content and titratable acidity (year 2015 above, year 2017 below) as affected by treatments (letters indicate significant differences at $P<0.05$ )

In this respect, the mechanisms underlying the effect of antitranspirant compounds on berry acidity should receive more targeted research, focusing also on the fate of the two main organic acids (malic and tartaric) in the grape berry. Finally, as in other studies $[12,16]$ a postveraison reduction of the canopy area obtained by manually pulling the leaves close to the fruiting zone was found able to delay sugar accumulation in Sauvignon blanc berries with only minor modification of their final titratable acidity.

\section{Conclusions}

Both the defoliation treatment and the antitranspirant application were found able to control ripening dynamic of grapevine berries. When a threshold value of $22^{\circ}$ Brix was fixed for the harvest, Pinolene-treated berries reached this value with approximately 10 and 15 days of delay in year 2015 and 2017, respectively. This result would, therefore, allow the postponement of the harvest until around mid-September, a season considered more suited for the obtainment of high quality white wines. As for the defoliation treatment, the delay in the ripening process of the berries could be estimated to approximately 5 days in both years. Further investigations are needed in order to better understand how to optimise the number and frequency of the antitranspirant applications, especially in relation with different meteorological conditions and rainfall regimes.

\section{References}

1. A. Seccia, G. Maggi, L'Informatore Agrario 13: 11-14. (2011)

2. H. Schultz, Australian Journal of Grape and Wine Research, 6(1), 2-12. (2000)

3. G.V. Jones, M.A. White, O.R. Cooper, K. Storchmann, Climatic Change, 73(3), 319-343. (2005)

4. M. Keller, Australian Journal of Grape and Wine Research, 16, 56-69. (2010).

5. L.B. Webb, P.H. Whetton, J. Bhend, R. Darbyshire, P.R. Briggs, E.W.R. Barlow, Nature Climate Change, 2(4), 259-264. (2012)

6. I. Filippetti, G. Allegro, N. Mohaved, C. Pastore, G. Valentini, C. Intrieri, Proc. 17th Int. Symp. Giesco, Asti - Alba: 259-262. (2011)

7. F. De Toda, J. Sancha, P. Balda, South African Journal of Enology and Viticulture, 34(2), 246. (2013)

8. A. Palliotti, S. Tombesi, O. Silvestroni, V. Lanari, M. Gatti, S. Poni, Scientia Horticulturae, 178, 4354. (2014)

9. A. Cartechini, A. Palliotti, American Journal of Enology and Viticulture, 46(2), 227-234. (1995).

10. A. Palliotti, S. Poni, J.G: Berrios, F. Bernizzoni, Australian Journal of Grape and Wine Research, 16(3), 426-433. (2010).

11. A. Palliotti, F. Panara, F. Famiani, P. Sabbatini, G.S. Howell, O. Silvestroni, S. Poni, American 
Journal of Enology and Viticulture, 64(3), 378-385. (2013).

12. A. Palliotti, F. Panara, O. Silvestroni, V. Lanari, P. Sabbatini, G.S. Howell, S. Poni, Australian Journal of Grape and Wine Research, 19(3), 369-377

(2013)

13. C. Intrieri, G. Allegro, G. Valentini, C. Pastore, E. Colucci, I. Filippetti, Vitis: Journal of Grapevine Research, 52(3), 117-124. (2013)

14. M. Gatti, M. Galbignani, A. Garavani, F. Bernizzoni, S. Tombesi, A. Palliotti, S. Poni, Australian Journal of Grape and Wine Research, 22(2), 245-255. (2016)

15. A. Caffarra, E. Eccel, Australian Journal of Grape and Wine Research, 17(1), 52-61. (2011)

16. G. Caccavello, M. Giaccone, P. Scognamiglio, M. Forlani, B. Basile, Australian Journal of Grape and Wine Research, 23(2), 226-239. (2017) 